\title{
EaD entre os ditames legais e a realidade concreta
}

\author{
Distance education between legal dictates and the concrete reality
}

\author{
Jussara Bueno de Queiroz Paschoalino \\ Centro de Apoio à Educação a Distância (CAED) \\ Universidade Federal de Minas Gerais (UFMG) \\ jussarapaschoalino@yahoo.com.br \\ Fernanda Araújo Coutinho Campos \\ Centro de Apoio à Educação a Distância (CAED) \\ Universidade Federal de Minas Gerais (UFMG) \\ fercout@hotmail.com
}

\author{
Inajara Salles Viana Neves \\ Faculdade de Educação \\ Universidade do Estado de Minas Gerais (UEMG) \\ inajara.salles@uemg.br \\ Fernando Selmar Rocha Fidalgo \\ Faculdade de Educação \\ Universidade Federal de Minas Gerais (UFMG) \\ rochafidalgo@yahoo.com.br
}

\begin{abstract}
Resumo Este texto resulta da análise do curso de Especialização em Gestão Escolar, ofertado pela Universidade Federal de Minas Gerais - UFMG a partir dos ditames legais para a efetivação da Educação a Distância. As reflexões se pautaram nas principais legislações sobre essa modalidade de ensino - Lei 9.394/1996; Decreto 5.622/2005; Decreto 5.773/2006; Portarias Normativas 1/2007 e 2/2007 (revogada); Referenciais de Qualidade para Educação Superior a Distância (2007) -, com o desígnio de compreender o desenvolvimento histórico da EaD no Brasil. Salientamos que, devido à inexistência de uma legislação com esse mesmo escopo para a pós-graduação, o documento que balisou este estudo foram os Referenciais de Qualidade para Educação Superior a Distância, especialmente no que se refere ao aspecto dos recursos humanos. As orientações determinadas nesse documento possibilitaram a análise do curso em questão, que foi implementado no periodo de 2008 a 2010. As reflexões realizadas e subsidiadas pelo documento supracitado, assim como a realidade do referido curso, permitiram concluir que essa especialização atendeu aos itens requeridos, principalmente no que se refere às ações para a constituição da equipe de trabalho: professores, tutores e pessoal técnico-administrativo para a manutenção da qualidade de um curso ofertado a distância. O sucesso do curso, explicitado no percentual de quase $80 \%$ de aprovação dos gestores em formação, fizeram o diferencial no âmbito nacional, demonstrando uma simetria harmoniosa entre a legislação e a proposta do curso.
\end{abstract}

Palavras-Chave: O resumo deve ser seguido de no máximo 6 palavras-chaves

\begin{abstract}
This text is the result of ongoing analysis of Specialization in School Management, offered by the Federal University of Minas Gerais - UFMG from legal directives for the effectiveness of Distance Education. The reflections were based in the main legislation on this type of education - Law 9,394/1996; Decree 5,622/2005; Decree 5,773 / 2006; Regulatory Ordinances 1/2007 and 2/2007 (repealed); Quality Benchmarks for Superior Distance Education (2007) - with the purpose of understanding the historical development of distance education in Brazil. We emphasize that, in the absence of legislation with the same scope for the graduate, the Quality Benchmarks documents for Higher Distance Education were the basis for this study, especially with regard to the aspect of human resources. The certain guidelines in this document enabled the analysis of the course in question, which was implemented in the 2008-2010 period. The reflections made and subsidized by the above document, as well as the reality of that course, showed that this specialization met the required items, mainly in respect to actions to make up the work team: teachers, tutors, technical and administrative staff to maintain the quality of a course offered at a distance. The success of the course, explained in the percentage of almost $80 \%$ approval of managers in training, made the difference at the national level, demonstrating a harmonious symmetry between the legislation and the proposed course.
\end{abstract}

Keywords: Distance Education. Legislation. Specialization in School Management. 


\section{Introdução}

O objeto central de análise deste texto é a Educação a Distância (EaD) nos tempos hodiernos, com foco em um curso de especialização lato sensu ofertado pela Faculdade de Educação da Universidade Federal de Minas Gerais (FaE/UFMG). Enfatizamos que a EaD se apresenta no contexto mundial como uma modalidade de ensino com diferentes percursos de consolidação. Nesse universo de possibilidades, ela se ancora em diversos aspectos relevantes, que contribuem para uma educação efetiva.

[...] no momento, a educação a distância está ganhando cada vez mais importância por causa de sua relação estrutural com muitas formas de aprendizagem on-line. $\mathrm{Na}$ medida em que consegue recorrer a 150 anos de experiência em ensino e aprendizagem assíncronos fora da sala de aula tradicional ou anfiteatro, pode contribuir substancialmente para a estrutura pedagógica atual da aprendizagem on-line. [1]

A importância da EaD nesse panorama maior se pauta em díspares indicadores, que vão desde as políticas públicas vigentes até a organização estrutural dos cursos. Assim, a EaD se encontra circunscrita na legalidade, mas os aspectos norteadores $\mathrm{e}$ as especificidades dos princípios para os cursos de especialização ainda gravitam sem força normativa de lei.

A reflexão proposta perpassou pela análise de alguns ordenamentos jurídicos da EaD respaldados pela Lei de Diretrizes e Bases da Educação (LDB 9.394/96), em especial artigo 80;[2] o Decreto 5.622/2005;[3] o Decreto $5.773 / 2006 ;[4]$ as Portarias Normativas 1/2007[5] e 2/2007[6] e os Referenciais de Qualidade para Educação Superior a Distância.[7] Salientamos que a escolha desses documentos perfila aspectos contundentes para a efetivação dos cursos.

A utilização dos Referenciais de Qualidade para Educação Superior a Distância,[8] por exemplo, fundamenta-se em dois pressupostos. Primeiramente, esses Referenciais, elaborados para o ensino superior, balizam a EaD no âmbito da especialização lato sensu, já que não há outro documento que trata especificamente da especialização nessa modalidade. $\mathrm{O}$ segundo pressuposto se deve às mudanças governamentais em função da extinção da Secretaria de Educação a Distância e à fase de transição que se encontra instaurada; a falta de um arcabouço de princípios deixa lacunas na reflexão sobre a organização, a atuação e a implicação social da especialização em EaD.
Assim, a análise da especialização em $\mathrm{EaD}$ se torna um relevante objeto, pois possibilita reflexões e críticas sobre como essa proposta se estabelece frente às orientações jurídicas. Conscientes da complexidade dessa discussão, optamos por direcionar nossas reflexões sobre essa formação para uma ótica singular sobre o curso de Especialização em Gestão Escolar oferecido pela FaE/UFMG.

A comparação entre os aspectos normativos e a realidade do curso em questão nos permitiu visualizar as construções da $\mathrm{EaD}$ ao longo do percurso e ainda evidenciaram outras a serem concebidas. Nesse sentido, foi necessário estabelecer uma direção a ser percorrida nessa reflexão.

Os Referenciais de Qualidade para Educação Superior a Distância[9] preconizam que a organização de um curso na modalidade $\mathrm{EaD}$ contempla três grandes áreas de constituição: aspectos pedagógicos, infraestrutura e recursos humanos. Ressaltamos que o recorte analítico deste estudo foi o aspecto dos recursos humanos.

Com intuito de melhor apresentar as reflexões, dividimos o texto em quatro partes conectadas. $\mathrm{Na}$ primeira, foi exposta, de forma sucinta, a legalização da $\mathrm{EaD}$ no contexto da política pública brasileira. $\mathrm{Na}$ segunda, apresentamos o curso de Especialização em Gestão Escolar oferecido pela FaE/UFMG e suas implicações e impactos na formação continuada de professores. $\mathrm{Na}$ terceira, desenvolvemos uma análise decorrente da comparação entre a lógica legal e a realidade do curso em questão. Por fim, na quarta parte, tecemos algumas considerações sobre as aproximações e distanciamentos entre os aspectos legais norteadores da $\mathrm{EaD}$ e o curso analisado.

\section{Contexto da EaD no Brasil: Aspectos Legais}

Sabe-se que a Educação a Distância não é uma prática educativa recente; ao contrário, ela é, de acordo com Peters[10], praticada desde o início da era cristã e tem ganhado cada vez mais importância, sendo uma das causas principais a possibilidade de relacionar estruturalmente diferentes formas de aprendizagem online. Para compreendê-la, é necessário recorrer aos 150 anos de experiência de ensino-aprendizagem assíncronos fora da sala de aula tradicional ou de grandes espaços aulistas. Ainda de acordo com o referido autor, a importância da $\mathrm{EaD}$ variou em períodos que se diferenciam pelo contexto tecnológico de cada época:

As primeiras experiências em educação a distância foram singulares e isoladas. No entanto, já eram de profunda importância para as pessoas implicadas, porque $o$ conteúdo era a religião e a controvérsia religiosa. [...] 
Estou me referindo aqui a São Paulo, que escreveu suas famosas epístolas a fim de ensinar às comunidades cristãs da Ásia Menor. [...] Ele usou as tecnologias da escrita e dos meios de transporte a fim de fazer seu trabalho missionário da pregação e do ensino face a face por pregação e ensino assíncronos e mediados.[11]

A história da humanidade apresenta diferentes formas de ensino-aprendizagem por meio da EaD. O autor salienta ainda que há três períodos distintos: o primeiro se consolidou por meio de projetos específicos que pavimentaram o caminho para o aprendizado síncrono. $\mathrm{O}$ segundo é representado pela educação por correspondência, que foi promovida, primeiramente, pela iniciativa privada e, posteriormente, o Estado passou a se interessar por essa modalidade de ensino. O terceiro refere-se à era EaD fomentada pela universidade aberta, um modo especial de ensinar e aprender, o que ocasionou mudanças significativas no ensino superior.

Assim, apesar de a EaD ter se estruturado mais eficazmente quando passou a estar associada aos recursos digitais, a modalidade não é recente; sua história decorre do desenvolvimento de ferramentas de comunicação que permitiram trocas de mensagens a longa distância.

Se, outrora, os recursos utilizados como mediadores da Educação a Distância (EaD) eram a correspondência, o rádio e a televisão, conforme salientam Peters[12], Moore e Kearsley[13] e Belloni[14], nos dias atuais, os ambientes virtuais de aprendizagem (AVA) têm prevalecido nas ofertas de ensino a distância, principalmente no ensino superior, seja na graduação ou na pós-graduação. A Educação a Distância, ao utilizar tecnologias da informação e da comunicação, adquire novos contornos e adjetivos, sendo, por vezes, denominada educação on-line. Portanto, a relação temporal é baseada na conveniência dos estudantes e dos docentes e estrutura-se em momentos síncronos e assíncronos, presenciais, não presenciais e semipresenciais, conforme salienta Araujo.[15]

$\mathrm{Na}$ perspectiva teórica, os estudiosos da área têm buscado definir a EaD de modos distintos, porém encontramos muitas similaridades, entre as quais se destacam suas características fundamentais: o uso de recursos tecnológicos como mediadores do processo ensino-aprendizagem, o tempo assíncrono entre os sujeitos e a distância física entre eles. Uma das concepções é a de que a Educação a Distância desenvolve "[...] novos modos de ensinar, utilizando as tecnologias da informação e da comunicação",[16] nos quais se apresentam como atores o professor coletivo e o estudante autônomo. Outra definição foi apresentada por Moore e Kearsley, que afirmam ser a EaD “[...] o aprendizado planejado que ocorre normalmente em um lugar diferente do local do ensino, exigindo técnicas especiais de criação do curso e de instrução, comunicação por meio de várias tecnologias e disposições organizacionais e administrativas especiais".[17]

Atualmente, a $\mathrm{EaD}$ se tornou tema frequente nas análises e propostas educacionais; as ações se multiplicam tanto no âmbito dos sistemas de ensino quanto nas áreas de formação e treinamento profissional.

No Brasil, ela é referendada pelo artigo 80 da LDB 9394/96,[18] possuindo o status de modalidade plenamente integrada ao sistema de ensino. É preciso esclarecer que essa legislação organiza a educação em níveis - básico e superior - e em modalidades - Educação a Distância, educação especial, educação de jovens e adulto e educação profissional. Por se tratar de uma modalidade, a $\mathrm{EaD}$ pode ser ofertada nos níveis básico e superior. No entanto, somente em 2005, com a regulamentação do referido artigo, ela se tornou uma modalidade na qual os processos de ensino-aprendizagem são desenvolvidos em lugares ou tempos diversos, com a utilização de meios tecnológicos para realização de atividades.[19] Por vezes, foi reconhecida apenas como um modo novo de fazer educação, levando-se em conta apenas aspectos relacionados aos meios modernos de comunicação.

Coerentemente com as orientações da LDB, o MEC publicou os Decretos de $\mathrm{n}^{\circ} 2494$, de 10 de fevereiro de 1998[20] e de $n^{\circ} 2561$, de 27 de abril de 1998,[21] além da Portaria 301, de 7 de abril do mesmo ano.[22] Esses dispositivos colocaram em evidência algumas questões básicas sobre EaD, com os sistemas estaduais e municipais passando a poder legislar sobre o ensino fundamental e médio a distância, o que inclui a Educação de Jovens e Adultos e a educação profissional de nível técnico. Já para a educação superior, além dos dispositivos mencionados, passaram a valer outros fixados pela legislação federal, como a Resolução CNE/CES n ${ }^{\circ} 1$, de 03 de abril de 2001, que estabelece normas para autorização, reconhecimento e renovação de pós-graduação stricto sensu na modalidade $\mathrm{EaD} ;[23]$ a Portaria de $n^{\circ} 4.361$, de 29 de dezembro de 2004, que define os processos de credenciamento e recredenciamento de Institutos de Educação Superior (IES) e de cursos de pós-graduação lato sensu;[24] o decreto $\mathrm{n}^{\mathrm{o}} 5.622$, de 19 de dezembro de 2005, que define a EaD como modalidade educacional na qual a mediação didático-pedagógica ocorre com a utilização de meios e tecnologias de informação e comunicação e que apresenta aspectos legais relativos à organização metodológica, gestão e avaliação dos processos educativos;[25] decreto $\mathrm{n}^{\mathrm{o}} 5.800$, de 08 de junho de 2006, que institui o Sistema Universidade Aberta do Brasil - UAB, cuja finalidade é expandir e interiorizar a oferta de cursos e programas de educação superior no Brasil;[26] a Portaria normativa $n^{\circ}$ 
2, de 10 de janeiro de 2007, que apresenta os processos de regulação e de avaliação do ensino superior na $\mathrm{EaD}$ [27]. É importante destacar, ainda, os Referenciais de Qualidade para Educação Superior a Distância, elaborados pelo Ministério da Educação, através da Secretaria de Educação a Distância, em agosto de 2007.[28]

O processo de regulamentação da educação superior está bastante avançado, mas não completamente contemplado, pelo fato de esse tema interessar diretamente a instâncias da administração federal (Conselho Nacional de Educação, Secretaria de Educação Superior e órgãos relacionados ao Ministério da Educação). Somente nos últimos anos estão se consolidando esforços mais articulados para a definição de padrões comuns para procedimentos de autorização, reconhecimento de estudos, padrões de qualidade e outras questões pertinentes a essa modalidade de ensino.

O contexto da educação brasileira, apesar de exibir uma realidade longe dos patamares internacionais, intensificou o discurso sobre a democratização, que teve seu ponto de legalidade na Lei 9.394/96: "[...] art. $80^{\circ}$ - O Poder Público incentivará o desenvolvimento e a veiculação de programas de ensino a distância, em todos os níveis e modalidades de ensino, e de educação continuada".[29] Dessa forma, abriu-se um panorama de formação que permitia a flexibilidade de horários para os alunos e uma educação de qualidade "[...] oferecida por instituições especificamente credenciadas pela União".[30] No gráfico 1, é possível verificar o crescimento das matrículas nos cursos a distância no período de 2003 a 2013:

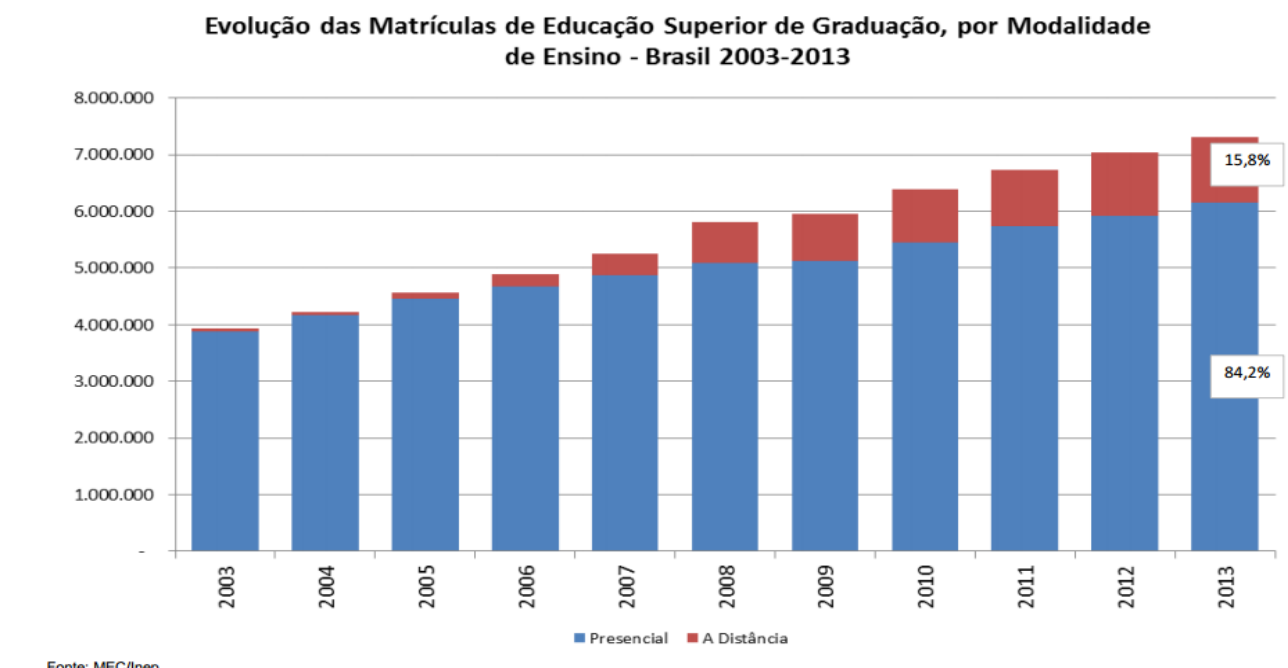

Fonte: MEC/nep

No período 2012-2013, a matrícula cresceu 3,9\% nos cursos presenciais e 3,6\% nos cursos a

distância. Os cursos a distância já contam com uma participação superior a 15\% na matrícula

de graduação.

Gráfico 1: Evolução das Matrículas de Educação Superior de Graduação, por Modalidade de Ensino - Brasil 2003-2013.

Fonte: MEC/Inep - 2013.

Os dados acima validam a hipótese de que a EaD tem contribuído para a expansão do ensino superior no Brasil e o acesso a ele. É importante destacar que os dados referem-se a matrículas para os cursos de graduação nos ISE, ilustrando aspectos que vêm sendo discutidos nos diferentes âmbitos educacionais. A seguir, na tabela 1, destacamos o número de matrículas no ano de 2013 por modalidade de ensino, categoria administrativa e organização acadêmica, de acordo com dados do Censo da Educação Superior 2013:[31]

Tabela 1 - Número de matrículas de graduação por modalidade de ensino; segundo a categoria administrativa e a organização acadêmica - Brasil - 2013

\begin{tabular}{|c|c|c|}
\hline Categoria & Organização Acadêmica & Matrículas \\
\hline
\end{tabular}




\begin{tabular}{|c|c|c|c|c|}
\hline Administrativa & & Total & Presencial & A Distância \\
\hline Total Geral & Total & $\mathbf{7 . 3 0 5 . 9 7 7}$ & $\mathbf{6 . 1 5 2 . 4 0 5}$ & $\mathbf{1 . 1 5 3 . 5 7 2}$ \\
\hline & Universidade & 3.898 .880 & 3.082 .155 & 816.725 \\
\hline & Centro Universitário & 1.154 .863 & 863.941 & 290.922 \\
\hline & Faculdade & 2.131 .827 & 2.094 .641 & 37.186 \\
\hline Pública & IF e CEFET & 120.407 & 111.668 & 8.739 \\
\hline & Total & $\mathbf{1 . 9 3 2 . 5 2 7}$ & $\mathbf{1 . 7 7 7 . 9 7 4}$ & $\mathbf{1 5 4 . 5 5 3}$ \\
\hline & Universidade & 1.655 .293 & 1.509 .479 & 145.814 \\
\hline & Centro Universitário & 25.692 & 25.692 & - \\
\hline & Faculdade & 131.135 & 131.135 & - \\
\hline & IF e CEFET & 120.407 & 111.668 & 8.739 \\
\hline Privada & Total & $\mathbf{5 . 3 7 3 . 4 5 0}$ & $\mathbf{4 . 3 7 4 . 4 3 1}$ & $\mathbf{9 9 9 . 0 1 9}$ \\
\hline & Universidade & 2.243 .587 & 1.572 .676 & 670.911 \\
\hline & Centro Universitário & 1.129 .171 & 838.249 & 290.922 \\
\hline & Faculdade & 2.000 .692 & 1.963 .506 & 37.186 \\
\hline
\end{tabular}

Tabela 1: Número de Matrículas de Graduação por Modalidade de Ensino; Segundo a Categoria Administrativa e a Organização Acadêmica - Brasil 2013.

Fonte: MEC/Inep - 2013. Adaptada pelas autoras.

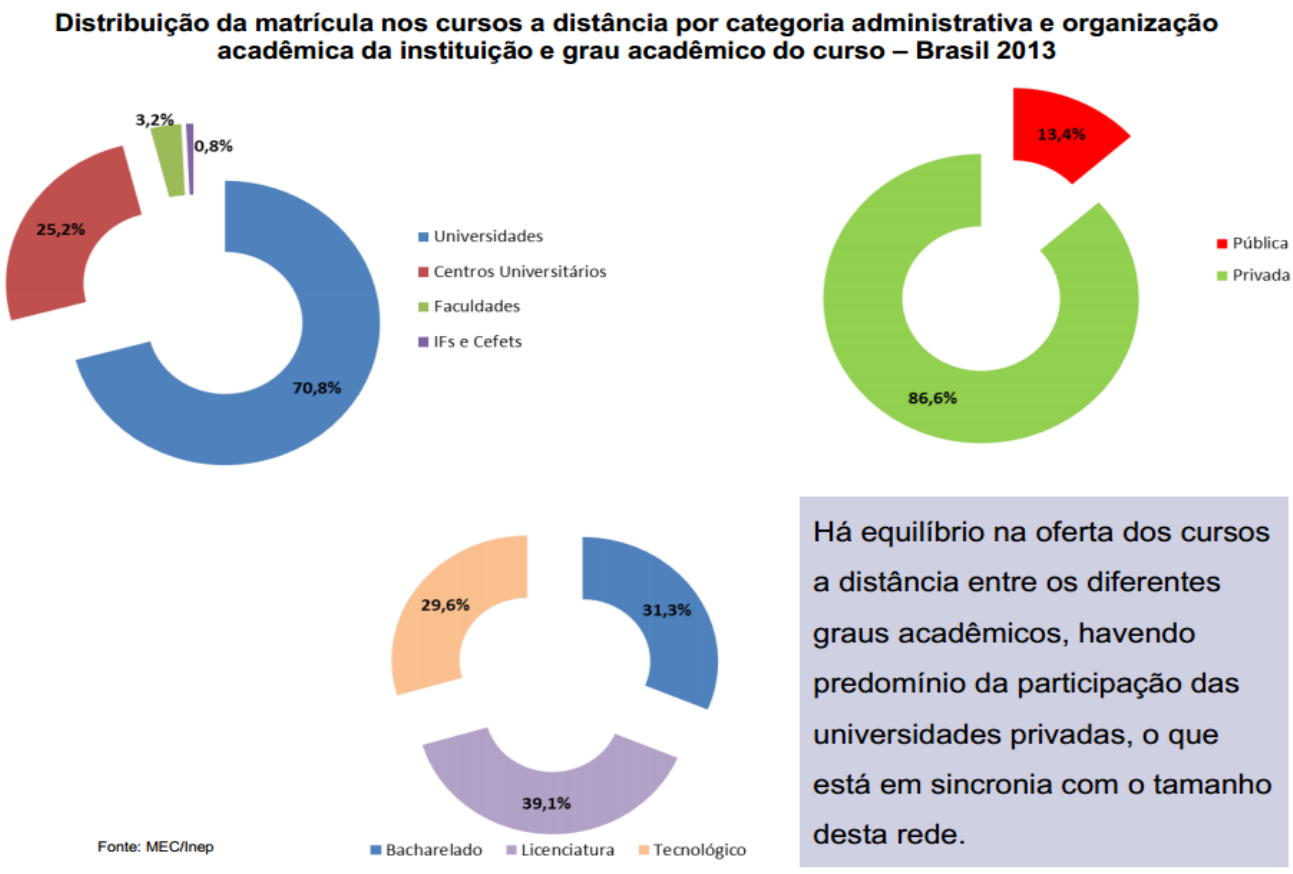

Gráfico 2: Distribuição de matrícula nos cursos a distância por categoria administrativa e organização acadêmica da instituição e grau acadêmico do curso - Brasil 2013

Fonte: MEC/Inep - 2013 .

Os dados demonstram que há um número maior de matrículas na modalidade $\mathrm{EaD}$ na categoria administrativa privada, com prevalência do setor privado sobre o público também no que se refere ao número de instituições e cursos a distância.
Nessa conjuntura, algumas experiências de oferta de cursos na modalidade $\mathrm{EaD}$ em instituições privadas, em especial no período de 2002 a 2007, aproveitaram-se da quase inexistência de ordenamentos jurídicos e não atenderam a requisitos básicos para garantir a qualidade 
do ensino superior. Diante desse quadro, é possível afirmar que a estrutura econômica foi determinante no delineamento inicial da $\mathrm{EaD}$ no Brasil. Portanto é de suma importância compreender minimamente os ordenamentos legais da $\mathrm{EaD}$ para uma melhor percepção de como foi delineada a oferta dessa modalidade educativa, em especial, como já citado, na esfera da especialização lato sensu.

O Decreto 5.622/2005 reiterou a competência do Ministério da Educação em promover os credenciamentos das instituições para a oferta de cursos e programas a distância para a educação superior, a graduação, a pósgraduação lato sensu e a pós-graduação strito sensu.[32] Dessa forma, foi se consolidando o ordenamento jurídico para a Educação a Distância, que, posteriormente, foi se desdobrando em outras orientações.

Assim, em junho de 2006, foi promulgado o Decreto 5.773, que "[...] dispõe sobre o exercício das funções de regulação, supervisão e avaliação de instituições de educação superior e cursos superiores de graduação e sequenciais no sistema federal de ensino".[33] No que tange a EaD, esse decreto atribuiu à Secretaria de Educação a Distância competência para credenciar e supervisionar os cursos ofertados pelas instituições públicas.

No aspecto avaliativo dos cursos, as Portarias Normativas 1/2007[34] e 2/2007[35] apresentaram as regulamentações voltadas a essa questão, sendo que a primeira dispunha sobre a avaliação dos cursos pelo Exame Nacional de Desempenho de Estudantes (ENADE) e a segunda (revogada) tratava "[...] dos procedimentos de regulação e avaliação da educação superior na modalidade a distância".[36]

A regulamentação da Educação a Distância também se fez presente na Resolução n. 1, de 8 de junho de 2007, que normatizou os cursos de pós-graduação lato sensu, em nível de especialização, reiterando a formação a distância já estabelecida na Lei 9.394/96 e determinando seu funcionamento: "Parágrafo único. Os cursos de pósgraduação lato sensu oferecidos a distância deverão incluir, necessariamente, provas presenciais e defesa presencial individual de monografia ou trabalho de conclusão de curso".[37]

Esse respaldo legal credenciou e sistematizou a modalidade de $\mathrm{EaD}$, permitindo repensar a educação na sua dimensão mais ampla. Nesse sentido, a educação, pelo prisma da $\mathrm{EaD}$, também se configurou pelos Referenciais de Qualidade para Educação Superior a Distância,[38] cujas regulamentações evidenciaram as singularidades da $\mathrm{EaD}$ e suas especificidades nas concepções teóricas e metodológicas, definindo sua organização e implantação.
Assim, os Referenciais de Qualidade para Educação Superior a Distância, ancorados na dinâmica de avaliação do Ministério da Educação (MEC), forneceram uma direção para os cursos que foram autorizados, na tentativa de garantir a qualidade da $\mathrm{EaD}$ em todo o território brasileiro. Os diferentes cursos de $\mathrm{EaD}$ e suas múltiplas formas de organização não poderiam perder o foco maior, que se circunscreve no entendimento da "[...] compreensão de EDUCAÇÃO como fundamento primeiro, antes de se pensar no modo de organização: A DISTÂNCIA".[39]

Nessa lógica, a $\mathrm{EaD}$ se insere, primeiramente, na busca por uma educação democrática e de qualidade, em comunhão com os aspectos legais, em todo território brasileiro, mantendo a especificidade de permitir nuances de atuações distintas. Assim,

[...] embora a modalidade a distância possua características, linguagem e formato próprios, exigindo administração, desenho, lógica, acompanhamento, avaliação, recursos técnicos, tecnológicos, de infraestrutura e pedagógicos condizentes, essas características só ganham relevância no contexto de uma discussão política e pedagógica da ação educativa.[40]

A partir desse entendimento, a $\mathrm{EaD}$ não se distancia do projeto educacional do nosso país; ao contrário, apresenta características próprias que possibilitam dirimir as lacunas educacionais. Destarte, para a eficácia da EaD, será necessário "[...] forte compromisso institucional em termos de garantir o processo de formação que contemple a dimensão técnico-científica para o mundo do trabalho e a dimensão política para a formação do cidadão".[41]

A formação de qualidade se fundamenta numa complexidade que deve levar em conta a abordagem sistêmica da educação. Diante desse enredamento, os aspectos normativos da $\mathrm{EaD}$ " [...] devem compreender categorias que envolvem, fundamentalmente, aspectos pedagógicos, recursos humanos e infraestrutura".[42]

Nesse sentido, a $\mathrm{EaD}$, numa dinamicidade própria, torna-se complexa e os detalhamentos para a sua efetiva qualidade exigem respostas aos termos normativos construídos, os quais trouxeram a relevância da $\mathrm{EaD}$ e delinearam contornos para que sua consolidação expressasse tal qualidade.

Neste estudo, fizemos o recorte pela categoria recursos humanos, apresentada de acordo com os Referenciais de Qualidade para Educação Superior a Distância.[43] Porém, antes, apresentaremos o curso que foi objeto de nossa análise. 


\section{A formação do gestor educacional na EaD}

O curso de Especialização em Gestão Escolar foi uma iniciativa do MEC e se configurou por meio Programa Nacional Escola de Gestores da Educação Básica Pública, que faz parte das ações do Plano de Desenvolvimento da Educação (PDE). Foi concebido a partir da necessidade da construção de processos de gestão coerentes com a concepção da qualidade social da educação, fundamentado nos princípios da administração pública moderna e em padrões de gerenciamento de instituições públicas, com intuito de qualificar os profissionais gestores das escolas da educação básica do sistema público de ensino, por meio de cursos à distância, ofertados por instituições de ensino superior públicas em parceria com o MEC.

Esse programa nacional de formação em serviço para os gestores escolares trouxe uma nova tessitura para a educação. Sua implementação se deu no ano de 2005, em caráter piloto, com 400 participantes, sendo ministrado pelo Instituto Nacional de Estudos e Pesquisas Educacionais Anísio Teixeira (INEP). Entretanto, em 2006, adquiriu uma nova dimensão e passou a ser coordenado pela Secretaria de Educação Básica do Ministério da Educação (SEB/MEC), em parceria com as universidades federais.

O propósito de uma formação que admitisse a conjugação do trabalho real com a teoria possibilitaria uma conotação diferente daquela dos cursos simplesmente acadêmicos. Assim, a proposta era possibilitar o repensar da educação pelo viés gestor, com as perspectivas de democratização e qualificação educacionais.

[...] A efetivação de um projeto articulado de formação (rede) de gestores objetiva, entre outros, institucionalizar $o$ atendimento da demanda de formação continuada para gestores escolares; contribuir com a qualificação da ação docente, sobretudo nos processos de organização e gestão democrática da escola, visando propiciar a consolidação de uma escola de qualidade para todos; institucionalizar e fortalecer o trabalho coletivo como meio de reflexão teórica e construção da prática pedagógica, contribuir com o desenvolvimento da autonomia intelectual e profissional dos docentes/gestores e propiciar projetos articulados de formação, bem como a troca sistemática de experiências e projetos de formação continuada entre as IFES, os sistemas de ensino e a SEB/MEC.[44]
Nesse novo cenário, ao lançar o Programa Nacional Escola de Gestores da Educação Básica Pública, o MEC deixou evidenciada a necessidade de repensar os rumos da escola. Como foco da formação, o gestor assumiria o papel de incitar as mudanças necessárias para a transformação das escolas. Dessa maneira, o curso de Especialização em Gestão Escolar delimitou dois objetivos gerais:

[...] formar, em nível de especialização (lato sensu), gestores educacionais efetivos das escolas públicas da educação básica, incluídos aqueles de educação de jovens e adultos, de educação especial e de educação profissional. [...] Contribuir com a qualificação do gestor escolar na perspectiva da gestão democrática e da efetivação do direito à educação escolar com qualidade social.[45]

Com duração de 400 horas, o foco da formação dos dirigentes, associado à formação em serviço, tinha em sua teleologia a melhoria da educação básica e elevação do índice do IDEB.

[...] o curso será estruturado em três eixos vinculados entre si: o direito à educação e a função social da escola básica; políticas de educação e a gestão democrática da escola; Projeto Político - Pedagógico e Práticas Democráticas na Gestão Escolar. Esses eixos estão consubstanciados em seis Salas Ambientes, além de um ambiente introdutório à plataforma Moodle e ao Curso de Especialização.[46]

O curso proposto para a formação dos gestores escolares já trazia um desenho arquitetado, porém possibilitava flexibilidade para sua efetivação. As diferenças das regiões brasileiras demarcaram diferenças na implementação do curso e em seu impacto. Entretanto, na complexidade das funções gestoras, profissionais dos diversos estados brasileiros apresentaram algumas similaridades, dentre as quais destacamos três pontos de conflitos no trabalho.

Um deles é reconhecido na lacuna de uma formação específica capaz de subsidiar as ações desses gestores frente aos dilemas do cotidiano, que não são poucos. Esses gestores conviviam com indisciplina, violência e, muitas vezes, com o adoecimento do docente.[47] Nesse âmbito, o curso de Especialização em Gestão Escolar veio suprir essa carência de formação e permitir uma interlocução mais ampla a respeito de problemas que não circulavam apenas no interior das escolas, mas que extrapolavam e impactavam toda a sociedade. 
Outro aspecto era a administração dos espaços e recursos destinados à escola, que foi intensificada a partir da descentralização financeira.[48] Nesse sentido, as dificuldades eram referentes à construção da autonomia escolar.

O terceiro ponto de conflito era a cobrança acirrada pela qualidade educacional; a figura do gestor escolar passou a ser a imagem do processo de edificação de uma escola transformada pela qualidade.[49] Essa qualidade passou a ser mensurada por mecanismos de avaliações externas, que resultaram em indicativos como o Índice de Desenvolvimento da Educação Básica (IDEB), que impuseram uma nova visão de educação.

Nessa lógica, o curso de Especialização em Gestão Escolar, mesmo não esperando uma hegemonia monolítica, tinha o intuito de possibilitar uma sintonia nas gestões escolares, por meio de uma reflexão sobre o trabalho, com vistas a mudanças de ação.

Mas quando se trata de políticas públicas as configurações são múltiplas, pois “"[...] são sempre suscetíveis de serem postos em questão, através de um processo constante de redefinição da estrutura, e, portanto, dos limites dos campos políticos".[50]

Assim, para tentar entender esses impasses das políticas de formação, optamos por analisar o Curso de Especialização de Gestão Escolar da Universidade Federal de Minas Gerais (UFMG), ministrado no período de 28 de agosto de 2008 a 31 de janeiro de 2010, cuja organização possibilitou refletir sobre a sua complexidade e analisar alguns aspectos gerais da $\mathrm{EaD}$.
A parceria entre a UFMG e a União Nacional dos Dirigentes Municipais de Educação (Undime) permitiu a organicidade do curso. Considerando tal realidade, a Undime arrolou a demanda e a pré-seleção de gestores escolares que estavam de acordo com os critérios instituídos pelo Programa Escola de Gestores do MEC. A Universidade Federal de Minas Gerais/UFMG ficou responsável pela seleção acadêmica, a partir das listas de nomes apresentada pela Undime; pela organização dos alunos por turmas, de acordo com os polos; pelas matrículas e por todas as questões administrativas do referido curso. A identificação dos polos, o contato com os municípios e a seleção dos professores da educação básica que atuaram como assistentes de turma foi realizada pela Undime-MG.

Essa formação em serviço atingiu 400 alunos em 68 cidades do Estado de Minas Gerais, possibilitando-os repensar a prática profissional e promovendo a interlocução desses gestores com a literatura acadêmica. A dinamicidade da formação evidenciou a mudança de concepções de educação, expressa nas atividades desenvolvidas ao longo do curso.

A complexidade do trabalho desenvolvido na escola e os impasses gerenciais dos gestores escolares se manifestaram nas disciplinas do curso; na defesa do Trabalho de Conclusão do Curso (TCC), ficou evidenciada a articulação lógica reflexiva elaborada por eles. O desempenho significativo dos gestores no curso pode ser ilustrado pela aprovação de aproximadamente $80 \%$ deles e uma reprovação pequena, de menos de $10 \%$, comprovando a qualidade e o reconhecimento do curso, bem como assegurando suas próximas edições.

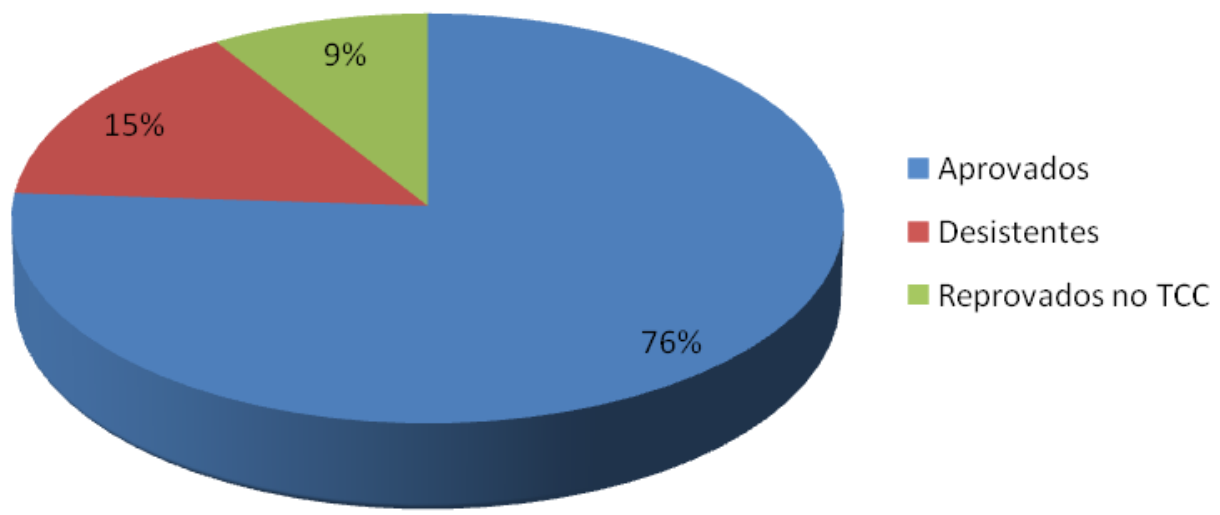

Gráfico 3: Situação Final do Curso de Especialização em Gestão Escolar.

Fonte: MEC/Inep - 2013.

As peculiaridades do curso de Especialização em Gestão Escolar mantidas pela formação oferecida pela
UFMG garantiram o sucesso do projeto. Nesse sentido, é importante considerar que os dados quantitativos 
certificaram esse lugar de destaque, em comparação com a realidade brasileira; o índice de desistências de $15 \%$ pode ser considerado baixo se comparado com as medias contabilizadas em cursos de EaD. Vale salientar que, pelos dados obtidos pela Associação Brasileira de Educação a Distância - ABED -, a evasão nos cursos de $\mathrm{EaD}$ autorizados pelo MEC foi de $18,6 \%$ em 2010 e $16,94 \mathrm{em} 2013$.

Em alguns estados, a implementação do curso oferecido pelo Programa Nacional Escola de Gestores da Educação Básica teve que superar muitas dificuldades. Foi o caso da experiência levada no estado do Espírito Santo:

Entre março e o final de maio, quando efetivamente teve início o curso, houve uma grande desistência. Alguns por circunstâncias alheias ao curso, outros pelo "receio" da plataforma e do nível de exigência das atividades. Imediatamente lançamos novo Edital para preenchimento de vagas e formação de banco de reservas. Sendo assim, tivemos que repetir a formação introdutória ao ambiente, pelo menos, até o mês de agosto de 2007. Essa foi apenas uma das medidas para contornar outro grande desafio: o da evasão. Outras medidas foram encontros presenciais nos pólos com os professores assistentes, visita dos professores de turma aos pólos, incentivo à formação de grupos de diretores e a recomendação explicitada em várias reuniões: "nenhum a menos". Essa recomendação era dirigida especialmente aos professores assistentes, que tinham contato mais direto e freqüente com os cursistas.[51]

Ao descrever a situação no Estado do Espírito Santo, os autores apontaram os desafios de minimizar as causas da evasão, um dos aspectos preocupantes nos cursos da $\mathrm{EaD}$, que demandou ações diferenciadas também no curso oferecido em Minas Gerais.

O índice de $9 \%$ de reprovação no TCC também foi pequeno em comparação aos índices nacionais e o percentual de $76 \%$ de aprovação constituiu um índice excelente se comparado aos resultados do mesmo curso em outros estados brasileiros.

A comparação dos dados demonstrou que, ao contrário da realidade da Escola de Gestores mineira, o índice de aprovação na mesma experiência de formação no estado do Paraná não foi satisfatório. Conforme apresentado por Souza[52], apenas $27 \%$ dos gestores concluíram a especialização lato sensu. $\mathrm{O}$ autor ainda explicita:
[...] no que se refere à lida dos problemas cotidianos, aqui parece que o curso conseguiu maior sucesso, uma vez que os TCC tomam essencialmente essas questões como roteiro de investigação e/ou reflexão. Todavia, vimos que a qualidade desses materiais de conclusão do curso é insuficiente, demonstrando que, mesmo com aumento da percepção investigativa nos diretores de escola pública, ainda há um longo caminho para torná-los sujeitos que tomem a pesquisa, a criatividade e a reflexão como instrumentos da gestão escolar.[53]

A análise apresentada pelo autor mostra a multiplicidade do Programa Escola de Gestores no território brasileiro, identificando que vários fatores interferiram nos resultados apresentados nas diferentes localidades.

Considerando o resultado alcançado na experiência da UFMG e a relevância dessa formação, apresentamos a seguir uma análise dos recursos humanos do referido curso, partindo dos Referenciais de Qualidade para Educação Superior a Distância.[54]

\section{Entre os ditames legais a respeito dos recursos humanos e a realidade analisada}

De acordo com os Referenciais de Qualidade para Educação Superior a Distância,[55] os recursos humanos devem configurar uma equipe multidisciplinar com funções de planejamento, implementação e gestão dos cursos a distância, considerando três categorias profissionais essenciais para garantia da qualidade: docentes, tutores e pessoal técnico-adminstrativo. Nesse sentido, a orientação da Resolução 1/2007 é:

[...] o projeto pedagógico deve especificar claramente em um quadro a qualificação dos docentes responsáveis pela coordenação do curso como um todo, pela coordenação de cada disciplina do curso, pela coordenação do sistema de tutoria e outras atividades concernentes. É preciso a apresentação dos currículos e outros documentos necessários para comprovação da qualificação dos docentes, inclusive especificando a carga horária semanal dedicada às atividades do curso. Além disso, a instituição deve indicar uma política de capacitação e atualização permanente destes profissionais.[56]

A partir dessa normatização, o projeto pedagógico do curso analisado nomeou coordenadores responsáveis com a titulação de doutores. Também indicou os professores doutores responsáveis por cada disciplina e especificou o 
calendário do curso, bem como a carga horária semanal. A UFMG, como instituição promotora, ofereceu formação para todos os profissionais envolvidos, por meio de oficinas e seminários.

As orientações para a organização do corpo docente estabeleciam que ele estivesse: "[...] vinculado à própria instituição, com formação e experiência na área de ensino e em Educação a Distância".[57] Por isso, foram contratados dezessete professores da UFMG, sendo quinze com doutorado e com experiência em EaD.

A escolha da equipe multidisciplinar do curso avaliado privilegiou, além da atuação profissional, a formação acadêmica de seus membros. $\mathrm{O}$ quadro abaixo expressa o panorama da equipe multidisciplinar:

\begin{tabular}{|l|l|}
\hline \multicolumn{2}{|c|}{ NIVEIS DE FORMAÇÃO } \\
\hline Doutores & 15 \\
\hline Mestres & 20 \\
\hline Especialistas & 25 \\
\hline
\end{tabular}

Tabela 2: Níveis de Formação da Equipe Multidisciplinar.

Fonte: UFMG (2010).

Em relação aos tutores, os Referenciais de Qualidade para Educação Superior a Distância[58] previam que esses profissionais tivessem: “[...] qualificação adequada ao projeto do curso".[59] Essa forma genérica de propor a composição dos tutores deixou interstícios que permitiram organizações diferenciadas. Entretanto, o próprio documento, ainda fazendo menção aos tutores de curso a distância, estabelece que: "[...] um sistema de tutoria necessário ao estabelecimento de uma Educação a Distância de qualidade deve prever a atuação de profissionais que ofereçam tutoria a distância e tutoria presencial".[60]

Nesse curso, a equipe de tutores foi composta por quarenta e três profissionais, que atuaram em duas instâncias diferentes. Uma equipe foi formada pelos tutores de sala, que eram os alunos da pós-graduação (mestrandos e doutorandos), os quais atuavam como tutores a distância. Já a equipe de tutores presenciais foi formada a partir da seleção de professores da educação básica com a titulação de especialistas, os quais atuavam nos polos. Com essa formatação, o curso de especialização analisado compôs sua equipe de acordo com as diretrizes legais, que ainda preconizavam:

[...] cabe ressaltar que as funções atribuídas a tutores a distância e a tutores presenciais são intercambiáveis em um modelo de educação a distância que privilegie forte mobilidade espacial de seu corpo de tutores. [...] Um programa de capacitação de tutores deve, no mínimo, prever três dimensões: a) capacitação no domínio específico do conteúdo; b) capacitação em mídias de comunicação; c) capacitação em fundamentos da $\mathrm{EaD}$ e no modelo de tutoria.[61]

Se o curso pesquisado escolheu previamente os tutores a distância e os tutores presenciais, o desafio de uma formação que contemplasse os três aspectos explicitados acima também fez parte de sua constituição. Esse entendimento era evidenciado pelos Referenciais de Qualidade para Educação Superior a Distância[62] quando determinou a formação e atuação desse tutor: "[...] tutor deve ser compreendido como um dos sujeitos que participa ativamente da prática pedagógica. Suas atividades desenvolvidas a distância e/ou presencialmente devem contribuir para o desenvolvimento dos processos de ensino e de aprendizagem e para o acompanhamento e avaliação do projeto pedagógico".[63]

No curso em análise, o cuidado com a formação permeou todo o processo, incluindo momentos regulares de encontros, reflexões e trocas de experiências. Essa dinâmica formativa dos tutores compreendeu dois movimentos. O primeiro foi a formação presencial, que permitiu o diálogo entre toda a equipe multidisciplinar. Vale salientar que o clima organizacional foi elemento de destaque para a efetivação do curso e que as reuniões presenciais possibilitaram também o entrosamento da equipe, bem como momentos de confraternização.

O outro movimento constitutivo da formação desses profissionais foram as interlocuções que aconteceram simultaneamente ao curso por meio da turma matriz, uma turma específica criada com objetivo de que todos os membros da equipe pudessem acessá-la para trazer contribuições que eram compartilhadas por todos, o que possibilitou um diálogo constante. Tal "diálogo torna se importante pedagogicamente porque nele linguagem, pensamento e ação estão intimamente relacionados e porque realizam o desenvolvimento individual e social do ser humano".[64]

À luz dessa contribuição, é possível compreender as interligações e aprendizagens ocorridas pelo processo dialógico instaurado pela sala matriz, que oportunizou uma coesão de ideias, concepções e ações pedagógicas do grupo. Na avaliação do curso, a criação da turma matriz apresentou o ambiente do curso e sua estrutura atendeu as necessidades da equipe. Como somente os professores tinham acesso a ela, foram realizados testes para avaliar e averiguar as possíveis falhas e dificuldades nas atividades que foram propostas para os alunos. Tal iniciativa serviu de ambiente de aprendizagem para os próprios professores, que realizam ali as tarefas propostas e as 
discutiam com os Coordenadores de Sala Ambiente. A partir dessa vivência, foram apresentadas propostas de alteração, que foram repassadas pela Coordenação de Assistência e Suporte Tecnológico às outras turmas. Também foram adicionados alguns recursos para facilitar a visualização, a busca e a pesquisa no ambiente virtual, tanto para os cursistas quanto para os professores.

A partir desta experiência, foi possível vislumbrar o constante movimento de interação entre todos os membros da equipe multidisciplinar, o que acarretou um entrosamento que facilitou à aprendizagem.

O trabalho articulado dessa equipe refletiu os princípios dos Referenciais de Qualidade para Educação Superior a Distância, segundo os quais “[...] é enganoso considerar que programas a distância minimizam o trabalho e a mediação do professor. Muito pelo contrário, nos cursos superiores a distância, os professores vêem suas funções se expandirem".[65]

As demandas da EaD fizeram com que os professores se desdobrassem para o atendimento aos alunos; dos docentes eram exigidas as seguintes habilidades:

[...] a) estabelecer os fundamentos teóricos do projeto; b) selecionar e preparar todo o conteúdo curricular articulado a procedimentos e atividades pedagógicas; c) identificar os objetivos referentes a competências cognitivas, habilidades e atitudes; d) definir bibliografia, videografia, iconografia, audiografia, tanto básicas quanto complementares; e) elaborar o material didático para programas a distância; f) realizar a gestão acadêmica do processo de ensino-aprendizagem, em particular motivar, orientar, acompanhar e avaliar os alunos. g) avaliar-se continuamente como profissional participante do coletivo de um projeto de ensino superior a distância.[66]

Para atender a essas demandas específicas, além das orientações dadas pelo próprio $\mathrm{MEC}$, a equipe como um todo se articulou para direcionar os encaminhamentos necessários. Assim, a turma matriz se tornou permanente, pois permitia o diálogo, a reflexão, a análise e, sobretudo, a construção de uma simetria da lógica do grupo; cada detalhe do curso ou de seus membros era pontuado nessa turma específica. Dessa forma, a organização das oficinas e a preparação dos encontros foram aspectos discutidos e trabalhados com a participação coletiva da equipe multidisciplinar.

Os Referenciais de Qualidade para Educação Superior a Distância também trouxeram critérios para os componentes do corpo técnico-administrativo: "[...] integrado ao curso e que presta suporte adequado, tanto na sede como nos polos; apoio à participação dos alunos nas atividades pertinentes ao curso, bem como em eventos externos e internos".[67] Esse documento também especificava as atividades a serem desenvolvidas por esses profissionais, que abrangiam duas áreas distintas e interligadas:

[...] as atividades desempenhadas por esses profissionais envolvem duas dimensões principais: a administrativa e a tecnológica. $\mathrm{Na}$ área tecnológica, os profissionais devem atuar nos pólos de apoio presencial em atividades de suporte técnico para laboratórios e bibliotecas, como também nos serviços de manutenção e zeladoria de materiais e equipamentos tecnológicos, enquanto que a atuação destes profissionais, nas salas de coordenação dos cursos ou nos centros de educação a distância das instituições, tem como principais atribuições o auxílio no planejamento do curso, o apoio aos professores conteudistas na produção de materiais didáticos em diversas mídias, bem como a responsabilidade pelo suporte e desenvolvimento dos sistemas de informática. [...] No que tange à dimensão administrativa, a equipe deve atuar em funções de secretaria acadêmica, no registro e acompanhamento de procedimentos de matrícula, avaliação e certificação dos alunos, envolvendo o cumprimento de prazos e exigências legais em todas as instâncias acadêmicas; bem como no apoio ao corpo docente e de tutores nas atividades presenciais e a distância, distribuição e recebimento de material didático, atendimento a alunos usuários de laboratórios e bibliotecas, entre outros.[68]

O curso em análise contou com o suporte técnicoadministrativo de uma secretaria implantada e os técnicos estabeleceram uma dinâmica constante de diálogo e parceria para suprir as dificuldades encontradas. Além de cumprir as funções especificadas nos Referenciais de Qualidade para Educação Superior a Distância,[69] esses profissionais tiveram duas ações principais: o contato com os alunos por telefone e o esclarecimento de dúvidas relacionadas ao acesso tecnológico. Ademais, a reciprocidade que estabeleceram com os outros membros da equipe multidisciplinar resultou numa coesão de equipe que foi um diferencial para a efetivação da proposta. $\mathrm{O}$ trabalho de coordenação possibilitou a formação em serviço, não só dos gestores escolares, mas de todo o corpo da equipe multidisciplinar

\section{Considerações Possíveis}

A EaD já se configura como uma modalidade de educação capaz de promover a democratização do ensino. Historicamente, desde 1970, presenciamos em outros 
países incrementos de políticas públicas com o objetivo explícito de favorecer formação pela $\mathrm{EaD}$, principalmente na Espanha, na Alemanha e na Inglaterra. Nesses países, tiveram início as universidades públicas com o ensino a distância, "[...] voltadas ao atendimento de milhares de estudantes trabalhadores com custos mais baixos, e, ao longo da experiência que acumularam, conseguiram obter bom padrão de qualidade nos programas desenvolvidos".[70]

No Brasil, diferentemente das iniciativas dos países europeus, a implementação da Educação a Distância nas universidades é recente; só "[...] em 1992 foi criada uma Coordenadoria Nacional de Educação a Distância e, em 1995, a secretaria de Educação a Distância (SEED)".[71] Essa trajetória, que não pretendemos elucidar detalhadamente por não constituir o foco deste trabalho, vale ser lembrada, pois ainda está eclipsada no cenário brasileiro da EaD.

Os textos normativos traçaram aspectos relevantes para a implementação da $\mathrm{EaD}$, contudo, o que pode ser constatado nos estudos teóricos sobre o assunto é que ainda há um longo caminho até o reconhecimento dessa modalidade de ensino como direito à educação pública e de qualidade.

Vale salientar que o curso de Especialização em Gestão Escolar, analisado a partir das prerrogativas legais, foi embasado nos princípios de uma formação de qualidade. Em consonância com a proposta do MEC, esse curso conseguiu traçar suas metas e atingir os objetivos pretendidos:

A formação continuada aqui proposta, visa, sobretudo, contribuir com o desenvolvimento profissional do professor gestor e com a melhoria na qualidade dos processos de organização e gestão da escola. Tal compreensão pauta-se em uma concepção de formação de professores que contemple a tematização de saberes e práticas num contexto de desenvolvimento profissional permanente.[72]

Nesta análise, em que o nosso olhar se concentrou em buscar os princípios de formação em $\mathrm{EaD}$, avaliamos os recursos humanos utilizados e a coesão da formação da equipe de trabalho. Dessa forma, consideramos que foi evidente a aproximação entre as normatizações existentes e a concretização do curso.

Também consideramos importante destacar que a organização do curso, por estar ancorada na equipe de profissionais (docentes, tutores e pessoal técnicoadministrativo), apresentou resultados que ultrapassaram os objetivos iniciais; o trabalho coletivo foi o propulsor dessa experiência.

Reiteramos, ainda, a compreensão, embasada nos Referenciais de Qualidade para Educação Superior a Distância,[73] de que a finalidade primeira é a educação, dentro da qual a $\mathrm{EaD}$ configura-se apenas como uma modalidade de ensino. Esse pressuposto amplia a possibilidade de enxergar uma dinâmica de educação que extrapole os princípios de uma universidade estática e abre novas perspectivas de uma visão do futuro. Segundo Peters,

A universidade do futuro está aberta a toda pessoa que pode participar do ensino com sucesso, portanto, também para muitos adultos em idade média ou adiantada. Ela não impõe locais e horários de estudo compulsórios. Portanto, o estudo pode ser iniciado, interrompido, e retomado exatamente de acordo com as necessidades da vida e da carreira profissional dos estudantes.[74]

A análise desse curso possibilitou a reflexão de que a universidade aberta proposta pelo autor também corroborou para a formação em serviço e para o sucesso do trabalho da equipe de profissionais envolvidos na realização do curso. Assim, de acordo com o exposto, podemos afirmar que, para a consolidação do princípio da educação, é necessário que as pessoas (recursos humanos) estejam, de fato, envolvidas nesse processo e comprometidas com ele.

\section{Referências}

[1]PETERS, O. Didática do Ensino a Distancia. Rio Grande do Sul: Unisul, 2003.

[2] BRASIL. Lei de Diretrizes e Bases da Educação Nacional. Lei n. 9654 de 20 de dezembro de 1996. Estabelece as diretrizes e bases da educação nacional. http://portal.mec.gov.br/arquivos/pdf/ldb.pdf, nov. 2013.

[3] BRASIL. Decreto n. 5.622 de 17 de dezembro de 2005. Regulamenta o art. 80 da Lei no 9.394, de 20 de dezembro de 1996, que estabelece as diretrizes e bases da educação http://www.planalto.gov.br/ccivil_03/_ nacional. 2006/2005/decreto/D5622.htm, nov. 2013.

[4] BRASIL. Decreto 5.773, de 9/5/2006. Dispõe sobre o exercício das funções de regulação, supervisão e avaliação de instituições de educação superior e cursos superiores de graduação e seqüenciais no sistema federal de ensino. 
http://www.planalto.gov.br/ccivil_03/_ato2004-

2006/2006/decreto/d5773.htm, nov. 2013.

[5] BRASIL. Ministério da Educação. Portaria normativa n. 1 , de 11 de janeiro de 2007. http://portal.mec.gov.br/seed/arquivos/pdf/legislacao/port aria1.pdf, mai. 2011.

[6] BRASIL. Ministério da Educação. Portaria normativa n. 2, de 10 de janeiro de 2007. Dispõe sobre procedimentos de regulação e avaliação de educação superior na modalidade a distância. http://portal.mec.gov.br/seed/arquivos/pdf/legislacao/port aria2.pdf, mai. 2011.

[7] BRASIL. Referenciais de Qualidade para Educação Superior a $\quad$ Distância. http://portal.mec.gov.br/seed/arquivos/pdf/

legislacao/refEaD1.pdf, jun. 2011.

[8] Ibidem.

[9] Ibidem.

[10] O. Peters. A educação a distância em transição. Editora UNISINOS, São Leopoldo, 2004.

[11] Ibidem.

[12] Ibidem.

[13] MOORE, M; KEARSLEY, G. A educação a distância: uma visão integrada. Cengage Learnin, São Paulo, 2007.

[14] BELLONI, M. L. Educação a Distância. 5. ed. Autores Associados, Campinas, 2001.

[15] ARAUJO, J. A. L. F. B. Educação online: um estudo sobre o blendedlearning na formação pós-graduada a partir da experiência de desenho, desenvolvimento e implementação de um protótipo web sobre a imagem. Tese de Doutorado, Universidade do Minho - Instituto de Educação e Psicologia, 2009.

[16] BELLONI, M. L. Educação a Distância. 5. ed. Autores Associados, Campinas, 2001.

[17] MOORE, M; KEARSLEY, G. A educação a distância: uma visão integrada. Cengage Learning, São Paulo, 2007, p. 2.

[18] BRASIL. Lei n. 9.394/96, de 23 de dezembro de 1996. Estabelece as Diretrizes e Bases da Educação Nacional. http://portal.mec.gov.br/arquivos/pdf/ldb.pdf, fev. 2011.

[19] BRASIL. Decreto n. 5.622 de 17 de dezembro de 2005. Regulamenta o art. 80 da Lei no 9.394, de 20 de dezembro de 1996, que estabelece as diretrizes e bases da educação nacional. http://www.planalto.gov.br/ccivil_03/_Ato2004-
2006/2005/decreto/D5622.htm, nov. 2013.

[20] MEC. Decreto de $\mathrm{n}^{\mathrm{o}} 2494$, de 10 de fevereiro de 1998.

http://portal.mec.gov.br/seed/arquivos/pdf/tvescola/leis/D 2494.pdf, fev. 2011.

[21] MEC. Decreto de $n^{\circ} 2561$, de 27 de abril de 1998. http://portal.mec.gov.br/seed/arquivos/pdf/tvescola/leis/D 2561.pdf, fev. 2011.

[22] MEC. Portaria 301, de 7 de abril de 1998. http://portal.mec.gov.br/seed/arquivos/pdf/tvescola/leis/p ort301.pdf, fev. 2011.

[23] CONSELHO NACIONAL DE EDUCAÇÃO. Resolução n. 1, de 03 de abril de 2001. Estabelece normas para autorização, reconhecimento e renovação de pós-graduação stricto sensu na modalidade $\mathrm{EaD}$. http://portal.mec.gov.br/seed/arquivos/pdf/tvescola/leis/C ES0101.pdf, fev. 2011.

[24] MEC. Portaria n. 4.361, de 29 de dezembro de 2004. define os processos de credenciamento e recredenciamento de Institutos de Educação Superior (IES) e de cursos de pós-graduação lato sensu. http://portal.mec.gov.br/seed/arquivos/pdf/port_4361.pdf, fev. 2011

[25] BRASIL. Decreto n. 5.622 de 17 de dezembro de 2005. Regulamenta o art. 80 da Lei no 9.394, de 20 de dezembro de 1996, que estabelece as diretrizes e bases da educação nacional. http://www.planalto.gov.br/ccivil 03/ Ato20042006/2005/decreto/D5622.htm, nov. 2013.

[26] BRASIL. Lei 5.800/2006, de 8 de junho de 2006. Dispõe sobre o Sistema Universidade Aberta do Brasil UAB. http://www.planalto.gov.br/ ccivil_03/_Ato20042006/2006/Decreto/D5800.htm, fev. 2011.

[27] BRASIL. Ministério da Educação. Portaria normativa n. 2, de 10 de janeiro de 2007. Dispõe sobre procedimentos de regulação e avaliação de educação superior na modalidade a distância. http://portal.mec.gov.br/seed/arquivos/pdf/legislacao/port aria2.pdf, fev. 2011.

[28] BRASIL. Referenciais de Qualidade para Educação Superior a Distância. http://portal.mec.gov.br/seed/arquivos/pdf/ legislacao/refEaD1.pdf, jun. 2011.

[29] BRASIL. Lei n. 9.394/96, de 23 de dezembro de 1996. Estabelece as Diretrizes e Bases da Educação Nacional. http://portal.mec.gov.br/arquivos/pdf/ldb.pdf, fev. 2011.

[30] Ibidem. 
[31] BRASIL. Censo da Educação Superior, INEP/MEC, 2013. http://portal.inep.gov.br/visualizar//asset publisher/6AhJ/ content/matriculas-noensinosuperiorcrescem 38 ? redirect $=\mathrm{http} \% 3 \mathrm{a} \% 2 \mathrm{f} \% 2$ fportal .inep.gov.br\%2f, out. 2014.

[32] BRASIL. Decreto n. 5.622 de 17 de dezembro de 2005. Regulamenta o art. 80 da Lei no 9.394, de 20 de dezembro de 1996, que estabelece as diretrizes e bases da educação http://www.planalto.gov.br/ccivil_03/_Ato20042006/2005/decreto/D5622.htm, nov. 2013.

[33] BRASIL. Decreto 5.773, de 9 de maio de 2006. Dispõe sobre o exercício das funções de regulação, supervisão e avaliação de instituições de educação superior e cursos superiores de graduação e seqüenciais no sistema federal de ensino. http://www.planalto.gov.br/ccivil_03/_ato20042006/2006/decreto/d5773.htm, nov. 2014.

[34] BRASIL. Ministério da Educação. Portaria normativa n. 1, de 11 de janeiro de 2007. http://portal.mec.gov.br/seed/arquivos/pdf/legislacao/port aria1.pdf, mai. 2011.

[35] BRASIL. Ministério da Educação. Portaria normativa n. 2, de 10 de janeiro de 2007. Dispõe sobre procedimentos de regulação e avaliação de educação superior na modalidade a distância. http://portal.mec.gov.br/seed/arquivos/pdf/legislacao/port aria2.pdf, mai. 2011.

[36] BRASIL. Referenciais de Qualidade para Educação Superior a Distância.

http://portal.mec.gov.br/seed/arquivos/pdf/

legislacao/refEaD1.pdf, jun. 2011.

[37] BRASIL. Resolução $\mathrm{n}^{\circ} 1$, de 8 de junho de 2007. http://portal.mec.gov.br/cne/arquivos/pdf/rces001_07.pdf, jun. 2011.

[38] BRASIL. Referenciais de Qualidade para Educação Superior a Distância.

http://portal.mec.gov.br/seed/arquivos/pdf/

legislacao/refEaD1.pdf, jun. 2011.

[39] Ibidem, p. 7, grifos do autor.

[40] Ibidem, p. 7.

[41] Ibidem, p. 7.

[42] Ibidem, p. 7.

[43] Ibidem.

[44] MEC. Diretrizes Nacionais do Curso de Pós Graduação em Gestão Escolar (2011). http://portal.mec.gov.br/seb/ arquivos/pdf/Escgest/es_diretr.pdf, jun. 2011.
[45] Ibidem.

[46] Ibidem.

[47] J. B. de Q. Paschoalino. O professor desencantado Matizes do trabalho docente. Armazém de Idéias, Belo Horizonte, 2009.

[48] A. R. de Souza. Programa Escola de Gestores e a Formação de Diretores no Estado do Paraná. In Anais do $25^{\circ}$ Simpósio Brasileiro e $2^{\circ}$ Congresso Iberoamericano de Política e Administração da Educação. Anpae, São Paulo, 2011.

[49] D. A. Oliveira. As políticas educacionais no governo Lula: rupturas e permanências. Revista Brasileira de Política e Administração da Educação - ANPAE, 25 (2): 185-384, 2009.

[50] P. Muller, Y. Surel. A Análise das Políticas Públicas. Educat, Pelotas, 2002.

[51] G. C. de Araújo, C. M. Schwartz. O Programa Nacional Escola de Gestores. In: C. M. Schwartz, G. C. de Araújo, P. da S. Rodrigues (Org.). Escola de gestores da educação básica: democracia, formação e gestão escolar: reflexões e experiências do Programa Nacional Escola de Gestores da Educação Básica no Estado do Espírito Santo. 2. ed. GM, Vitória, 2010. htpp://C:/Users/Windows/Downloads/democracia_forma cao_gestao_escolar.pdf, mai. 2012.

[52] A. R. de Souza. Programa Escola de Gestores e a Formação de Diretores no Estado do Paraná. In Anais do $25^{\circ}$ Simpósio Brasileiro e $2^{\circ}$ Congresso Iberoamericano de Política e Administração da Educação. Anpae, São Paulo, 2011.

[53] Ibidem.

[54] BRASIL. Referenciais de Qualidade para Educação Superior a Distância. http://portal.mec.gov.br/seed/arquivos/pdf/

legislacao/refEaD1.pdf, jun. 2011.

[55] Ibidem.

[56] BRASIL. Resolução ${ }^{\circ} 1$, de 8 de junho de 2007. http://portal.mec.gov.br/cne/arquivos/pdf/rces001_07.pdf, jun. 2011.

[57] Ibidem.

[58] BRASIL. Referenciais de Qualidade para Educação Superior a $\quad$ Distância. http://portal.mec.gov.br/seed/arquivos/pdf/ legislacao/refEaD1.pdf, jun. 2011.

[59] BRASIL. Resolução ${ }^{\circ} 1$, de 8 de junho de 2007. http://portal.mec.gov.br/cne/arquivos/pdf/rces001_07.pdf, jun. 2011. 
[60] Ibidem.

[61] Ibidem.

[62] BRASIL. Referenciais de Qualidade para Educação Superior a Distância. http://portal.mec.gov.br/seed/arquivos/pdf/ legislacao/refEaD1.pdf, jun. 2011.

[63] BRASIL. Resolução ${ }^{\circ} 1$, de 8 de junho de 2007. http://portal.mec.gov.br/cne/arquivos/pdf/rces001_07.pdf, jun. 2011.

[64] O. Peters. A educação a distância em transição. Editora UNISINOS, São Leopoldo, 2004, p. 80.

[65] BRASIL. Referenciais de Qualidade para Educação Superior a Distância. http://portal.mec.gov.br/seed/arquivos/pdf/ legislacao/refEaD1.pdf, jun. 2011.

[66] Ibidem.

[67] Ibidem.

[68] Ibidem.

[69] Ibidem.

[70] B. A. Gatti, E. S. S. Barreto. Professores do Brasil: impasses e desafios. UNESCO, Brasília, 2009, p. 89.

[71] Ibidem, p. 89.

[72] MEC. Diretrizes Nacionais do Curso de Pós Graduação em Gestão Escolar (2011). http://portal.mec. gov.br/seb/arquivos/pdf/Escgest/es_diretr.pdf, jun. 2011.

[73] BRASIL. Referenciais de Qualidade para Educação Superior a Distância. http://portal.mec.gov.br/seed/arquivos/pdf/ legislacao/refEaD1.pdf, jun. 2011.

[74] O. Peters. A educação a distância em transição. Editora UNISINOS, São Leopoldo, 2004. 